\title{
Does Illegal Immigration Empower Rightist Parties?
}

\author{
Ángel Solano García*†
}

May 2004

\begin{abstract}
The main goal of this paper is to analyze the political outcome in countries where the relevant issue in elections is the control of immigration. In particular we explore the consequences on the political outcome of the fact that parties are either ideological or opportunistic with respect to this issue. In order to do that we use a simple two-party political competition model in which the issues over which parties take positions are the level of border enforcement and the way it has to be financed. We show that an ideological rather than a pure opportunistic behavior gives parties an advantage to win the election. In particular, in most of the cases we consider we find that rightist parties have an advantage to win in countries where the relevant issue in election is illegal immigration. This result may help us to understand the recent success of anti-immigrant and rightist parties in several countries.
\end{abstract}

\section{Introduction}

The main goal of this paper is to analyze the political outcome in countries where the relevant issue in elections is the control of immigration. In particular

*I am deeply indebted to Enriqueta Aragonés for her patience, for motivating me and making me enjoy a lot my work. I also want to thank Humberto Llavador, Micael Castanheira and Santiago Sanchez-Pagés for their comments and suggestions, and Fundación Ramón Areces for financial support.

†International Doctorate in Economic Analysis. Departament d'Economia i d'Història Econòmica. Universitat Autònoma de Barcelona. 08193 Bellaterra (Barcelona) - Spain. 
we explore the consequences on the political outcome of the fact that parties are either ideological or opportunistic with respect to this issue. In order to do that we use a simple two-party political competition model in which the issues over which parties take positions are the level of border enforcement and the way it has to be financed. We show that an ideological rather than a pure opportunistic behavior gives parties an advantage to win the election. This result may help us to understand the recent success of anti-immigrant and rightist parties in several countries. ${ }^{1}$

The first question that we have to address is: why the control of immigration might be the relevant issue in elections?. In other words: why immigration is important for the host country's voters? Immigration has economic and noneconomic effects in the host country's society. Regarding the economic effects, there are empirical and theoretical papers that analyze the immigration's effect on natives' labor market conditions. ${ }^{2}$ There are also other papers exploring the fiscal effects of immigration on the governments' budget and on the provision of public goods. ${ }^{3}$ However, there are very few things said about non-economic effects of immigration in the host country's society. In this context Mayda (2003) looking at cross-country survey data finds evidence of a robust relationship between attitudes towards immigration and both security concern and cultural and national identity issues. In this paper we focus on the effect of immigration on security concern in the host country i.e. we focus on how immigration affects citizens' perception about the lack of security and delinquency in the host country.

Despite of the fact that immigration and delinquency may not be related, in many countries, the society actually links immigration with delinquency. In Europe, a survey requested by the European Commission points out that immigration is spontaneously accused of being a major source of insecurity in most EU-countries. An extreme example can be Greece in which a survey of the police shows that $92 \%$ of the surveyed population believed that the increase in the crime rate over the 90s has been caused by immigrant criminality (see Karidis,

\footnotetext{
${ }^{1}$ For example, the National Front headed by Jean Marie Le Pen in France, Haider's Freedom party in Austria, Fortuyn's party in the Netherlands or Berlusconi's party in Italy.

${ }^{2}$ See Borjas et al (1996)

${ }^{3}$ See Razin et al (2002)
} 
1998). Regarding the US, a poll (2000) shows that $70 \%$ of respondents thought that immigrants are the cause of higher crime rates (see Cooper, 2003). On the other hand, after the terrorist attacks of September 11, 2001, the social concern about insecurity rose in the US together with the society's fear of massive immigration.

Together with the current rise of migration flows, illegal immigration is rising very rapidly in some developed countries. In the US it is estimated that there were 8 to 11 million of illegal immigrants in 2003. Some countries in Europe as Italy, Greece and Spain are also receiving large numbers of illegal immigrants. Regarding the link between illegal immigration and the social perception of insecurity, there are a priori reasons to think that the link between illegal immigration and crime may be more real than the link between legal immigration and crime. First, illegal immigration has turned into smuggling and trafficking of people as a lucrative business by international crime syndicates. Frequently, those migrants are caught up in organized crime by these criminal gangs. ${ }^{4}$ Second, in general illegal immigrants face worse labor market conditions therefore they have a lower cost to switch to the crime sector. Empirical results on these assertions are rare because of the difficulty to obtain data about illegal immigration. Nevertheless, Coronado and Orrenius (2003) find that illegal immigration through the US-Mexican border is not related with property crimes but there is a significant positive correlation with violent crimes.

In our model we assume that there exists a positive relation between the number of illegal immigrants that enter the country and the natives' perception of the lack of security in the host country. Therefore, the number of illegal immigrants that enter the country affects negatively citizens' expected utility. Moreover, we assume that the effects of illegal immigration on citizens' utility may be different for different citizens. Regarding this assumption, Mayda (2003) finds empirical evidence that in developed countries unskilled workers' attitudes towards immigration are more negative than skilled ones. However, she finds that the opposite is true for developing countries. In order to make the analysis more general we do not consider any restriction about the relative intensity of skilled and unskilled workers' attitudes to immigration.

\footnotetext{
${ }^{4}$ See Budapest Group (1999).
} 
Additionally, illegal immigration is becoming an important political issue in many developed countries. An example of the increasing importance of illegal immigration in the political agenda is the growth of the governments' expenses devoted to deter it. For instance, the U.S. government has dramatically increased the enforcement of the U.S border over the last two decades, raising the enforcement budget of the U.S. Border Patrol from $\$ 290$ million in 1980 to $\$ 1.7$ billion in 1998 (in 1998 dollars). Also the number of hours that Border Patrol officers spent policing the Mexican border increased from 1.8 million in 1977 to 5.1 million in 1997. As a consequence of this increase of enforcement, border apprehensions rose from 200.000 in 1970 to 1.5 million in $1999 .{ }^{5}$ The European Union is also paying special attention to this issue as it was shown in the European Council meeting in Seville. ${ }^{6}$

In our model we assume that there exists an exogenous potential mass of illegal immigration that is willing to enter a country. The government of the country may implement a level of border enforcement in order to try to deter such illegal immigration from entering it. We can interpret the level of border enforcement as the government's expenses devoted to external border protection plus deportation costs. We assume that an increase in border enforcement would decrease the number of illegal immigrants entering the country although at a decreasing rate.

To finance border enforcement the government charges an ad valorem personal income tax on native workers. The Government may introduce a certain level of progressivity in the tax scheme charging a lower ad valorem personal income tax to low income workers than to high income ones. We assume that the government's budget constrain has to be balanced.

We analyze the political outcome of a two party electoral competition model. The choices of parties are the instruments described before: the level of border enforcement and the progressivity of the tax scheme. We suppose that parties are fully committed to implement the policy announced during the electoral campaign. We show two different scenarios depending on whether parties are

\footnotetext{
${ }^{5}$ See Orrenius (2001) and Hanson and Spilimbergo (2001).

${ }^{6}$ The President of European Comission, presently Romano Prody, proposed to strengthen the control of the external borders by developing the concept of an integrated and comprehensive "border strategy" for EU.
} 
opportunistic or ideological.

We find that when parties are opportunistic, the unique equilibrium outcome is that both parties win the election with the same probability and propose the same pair of policies. These equilibrium policies will coincide with the optimal policies for the median voter. Nevertheless, when parties are ideological the political outcome in equilibrium is that a unique party surely wins the election and the equilibrium policy implemented may be different from the optimal one for the median voter. Therefore, ideology gives one party an advantage to win the election.

Ideology of a party is defined in our model as a strong preference on one policy instrument. In particular, when parties are ideological we consider two possibilities: i) both parties' ideology is determined by the progressivity on taxes and ii) both parties' ideology is determined by the level of border enforcement. The first case could be applied to countries in which illegal immigration becomes an important issue very recently, and therefore, it can be supposed that parties would not have an ideological position on this issue yet. The second case could be applied to countries in which illegal immigration has been an important issue for some time, and therefore, it can be supposed that parties would already have an ideological position on this issue.

In this context, one of our main findings is that, in the presence of parties ideologically determined by the border enforcement, the more intense the relationship between insecurity and illegal immigration is for skilled workers, the more likely the most rightist party wins in developed countries (where the median voter is skilled). Also, the higher the number of potential illegal immigrants is, the more likely the rightist party wins in developed countries. Both results seem to be quite intuitive. We shall comment other results in the last section of the paper.

The rest of the paper is organized as follows: in Section 2 we formally describe the model. In Section 3 we analyze the properties of the voters' indirect utility functions with respect to the policy instruments. In Section 4 we focus on the political competition considering different scenarios where political parties are either opportunistic or ideological. Finally, in Section 6 we conclude and discus some results. 


\section{The Model}

Consider a country in which population is composed by native workers and illegal immigrants. In our model the number and role played by legal immigrants is negligible since we assume that they do not have a relevant effect on social insecurity and they cannot participate in elections.

\subsection{Native workers}

Native workers care about their private consumption and about the number of illegal immigrants living in the country $(I)$. We assume that illegal immigration has a negative effect on native workers' expected utility. This effect is induced by the natives' perception that illegal immigration rise delinquency and social insecurity. Native workers' expected utility function is assumed to take the following functional form:

$$
U_{i}\left(c_{i}, I\right)=c_{i}-\beta_{i} I,
$$

where $c_{i}$ is the consumption level of worker $i$ and $\beta_{i} \in R_{+}$a parameter which measures the impact of illegal immigration on the utility of worker $i$.

Native workers receive an income or salary $w_{i}$ which, after paying taxes, is spent fully in consumption. Hence, native workers' budget constraint can be written as:

$$
c_{i}=\left(1-t_{i}\right) w_{i} \quad i=u, s,
$$

where $t_{i}$ is the "ad valorem" personal income tax imposed on worker $i$ by the government. We assume that salaries are exogenously determined.

For simplicity let assume that there are only two types of native workers: skilled and unskilled, denoted by the subindex $i=u, s$. We assume that the number of skilled and unskilled workers is $S$ and $U$ respectively. We also assume that skilled workers' wage is higher than unskilled workers' one i.e. $w_{s}>w_{u}$.

\subsection{Illegal Immigration}

We assume that the amount of illegal immigration that enters the country depends on the amount of immigration which is willing to reach illegally the coun- 
try and it also depends on the resources devoted by the government to border enforcement. Suppose that there is a potential mass of immigrants that wants to enter illegally the country $(Y)$ and that only a fraction of this mass actually enters $(I \leq Y)$. That restriction on the entry is costly for the government which may spend a positive amount of money in border enforcing policy $(E)$. Thus, the number of illegal immigrants that enter the country can be written as $I(Y, E)$.

We assume that the number of illegal immigrants that enter the country (I) decreases with the level of border enforcement $(E)$, that is, $I_{E}(Y, E)<0$; and it increases with the number of potential illegal immigrants $(Y)$, that is $I_{Y}(Y, E)>0$. We interpret $I_{E}(Y, E)$ as a measure of efficacy of the border enforcement policy. We assume decreasing rates of return of $I$ with respect to the level of border enforcement, i.e. $I_{E E}(Y, E)>0$. That is, efficacy is decreasing on the level of border enforcement. Moreover, we assume that $I_{E Y}(Y, E)<0$, i.e. efficacy of border enforcement is increasing on the number of potential illegal immigrants. Finally, we assume that if the government spends no money in border enforcement all illegal immigrants will enter the country, i.e. $I(Y, 0)=Y$.

\subsection{Government's budget constraint}

The government uses taxes to fund the total resources spent in border enforcement policy. We assume that the government's budget is always balanced, that is,

$$
E=t_{u} U w_{u}+t_{s} S w_{s}
$$

Notice that all, workers in the same group (skilled or unskilled) receive the same salary and pay the same personal income tax. However, workers belonging to different groups obtain different salaries and may pay different personal income tax. We assume that the government may propose a certain level of progressivity in their tax schemes:

$$
t_{u}=\alpha t_{s} \quad \alpha \in[0,1],
$$

where $\alpha$ is the level of progressivity of the government's tax scheme. Notice 
that the tax scheme is more progressive as $\alpha$ is closer to 0 and conversely, when it is equal to 1 we are in the case of a pure proportional tax scheme.

From the government's budget constraint we have that the level of border enforcement $E$ offered by the government is the following function of the personal income tax imposed on skilled workers:

$$
E=t_{s}\left(\alpha U w_{u}+S w_{s}\right)
$$

\section{$3 \quad$ Indirect Utility functions}

Our main goal is to obtain the policy outcome of political competition, regarding the policy instruments. To do that we characterize the utility of the voters as a function of the government's policy instruments: the level of border enforcement $E$ and the level of progressivity of the taxes $\alpha$.

\subsection{Optimal $E$ for a fixed $\alpha$}

First, we compute the level of $E$ that maximizes the utility function of each type of voter (skilled or unskilled workers) for a given value of $\alpha$, subject to the worker's budget constraint. Since given a pair of values for $E$ and $\alpha$, the balanced GBC (government's budget constraint) defines a unique value for the taxes, we need to consider the GBC as an additional feasibility constraint in the maximization of the utility functions.

Thus, for a given $\alpha$, the optimal level of $E$ for skilled workers is the solution to the following problem.

$$
\left\{\begin{array}{cl}
\max _{E} & c_{s}-\beta_{s} I(Y, E) \\
\text { s.t. } & (2) \text { and }(5) .
\end{array}\right.
$$

Substituting both restrictions in the objective function the optimization problem can be written as:

$$
\max _{E} w_{s}\left(1-\frac{E}{\alpha U w_{u}+S w_{s}}\right)-\beta_{s} I(E, Y)
$$

Solving for the first order condition we obtain a condition on the marginal effect of $E$ over illegal immigration $I$ for skilled workers: 


$$
I_{E}\left(Y, E_{s}^{*}(\alpha)\right)=\frac{-w_{s}}{\beta_{s}\left(\alpha U w_{u}+S w_{s}\right)}
$$

This equation defines the level of border enforcement that maximizes ${ }^{7}$ the skilled workers' utility $\left(E_{s}^{*}\right)$ for a given value of $\alpha$.

Similarly, for a given $\alpha$, the optimal level of $E$ for unskilled workers is the solution to the following maximization problem:

$$
\left\{\begin{array}{c}
\max _{E} \quad c_{u}-\beta_{u} I(Y, E) \\
\text { subject to (2), (4) and (5). }
\end{array}\right.
$$

Notice that substituting (5) in (4) we obtain:

$$
t_{u}=\frac{\alpha E}{\alpha U w_{u}+S w_{s}}
$$

Substituting the restrictions in the objective function the optimization problem can be written as:

$$
\max _{E} w_{u}\left(1-\frac{\alpha E}{\alpha U w_{u}+S w_{s}}\right)-\beta_{u} I(E, Y)
$$

Solving for the first order condition we obtain a condition on the marginal effect of $E$ over illegal immigration $I$ for unskilled workers:

$$
I_{E}\left(Y, E_{u}^{*}(\alpha)\right)=\frac{-\alpha w_{u}}{\beta_{u}\left(\alpha U w_{u}+S w_{s}\right)}
$$

This equation defines the level of border enforcement that maximizes ${ }^{8}$ unskilled workers' utility $\left(E_{u}^{*}(\alpha)\right)$ for a given value of $\alpha$. Notice that for $\alpha=0$, since $I_{E}(Y, E)<0$ for all $E \in R^{+}$, the FOC is not satisfied and therefore, the optimal level of border enforcement for unskilled workers is the maximum feasible level, that is $E_{\max }=S w_{s}$.

Comparing the different optimal levels of border enforcement for skilled and unskilled workers we can state the following two propositions:

Proposition $1 E_{s}^{*}(\alpha)$ is increasing on $\alpha$ and $E_{u}^{*}(\alpha)$ is decreasing on $\alpha$

\footnotetext{
${ }^{7}$ The Second Order Condition is also satisfied since: $-\beta_{s} I_{E E}(E, Y) \leq 0 \quad \forall \beta_{s} \in R_{+}$

${ }^{8}$ The Second Order Condition is also satisfied since: $-\beta_{u} I_{E E}(E, Y) \leq 0 \quad \forall \beta_{u} \in R_{+}$.
} 
Proof. To prove that $E_{s}^{*}(\alpha)$ is increasing on $\alpha$ consider two different values of $\alpha_{1}$ and $\alpha_{2}$ such that, $\alpha_{2} \geq \alpha_{1}$. From the skilled workers' FOC we have that $I_{E}(Y, E)$ is an increasing function of $\alpha$. Hence, $I_{E}\left(Y, E_{s}^{*}\left(\alpha_{2}\right)\right) \geq I_{E}\left(Y, E_{s}^{*}\left(\alpha_{1}\right)\right)$ but since we assumed $I_{E E}(Y, E)>0$, this implies that $E_{s}^{*}\left(\alpha_{2}\right) \geq E_{s}^{*}\left(\alpha_{1}\right)$. Thus, $E_{s}^{*}(\alpha)$ is increasing on $\alpha$.

To prove $E_{u}^{*}(\alpha)$ is decreasing on $\alpha$, notice that by the same argument we need to show that $I_{E}\left(Y, E_{u}^{*}\left(\alpha_{1}\right)\right) \geq I_{E}\left(Y, E_{u}^{*}\left(\alpha_{2}\right)\right)$. But this is true iff:

$$
\begin{aligned}
\frac{\alpha_{1} w_{u}}{\beta_{u}\left(\alpha_{1} U w_{u}+S w_{s}\right)} & \leq \frac{\alpha_{2} w_{u}}{\beta_{u}\left(\alpha_{2} U w_{u}+S w_{s}\right)} \\
& \Leftrightarrow \\
\alpha_{1} \alpha_{2} U w_{u}+\alpha_{1} S w_{s} & \leq \alpha_{1} \alpha_{2} U w_{u}+\alpha_{2} S w_{s}
\end{aligned}
$$

Which is equivalent to say that $\alpha_{1} \leq \alpha_{2}$. Thus, it always holds and we obtain that $E_{u}^{*}(\alpha)$ is decreasing on $\alpha$.

This proposition says that when there is a decrease on the progressivity of the tax scheme skilled workers will prefer a higher level of border enforcement and unskilled workers will prefer a lower one. If the tax is more proportional skilled workers have to contribute less, in relative terms, in other words, $E$ becomes cheaper for skilled workers for more proportional tax schemes. Therefore, a government that tries to obtain the vote of skilled workers will propose a lower level of $E$ for more progressive tax schemes. Similarly a government that tries to obtain the vote of unskilled workers will propose a higher level of $E$ for more progressive tax schemes.

The next proposition shows that given a level of progressivity of the tax scheme $(\alpha)$ unskilled workers will prefer a higher level of border enforcement than skilled workers as long as the illegal immigration effect on their utility is high enough.

Proposition $2 E_{u}^{*}(\alpha) \geq E_{s}^{*}(\alpha) \quad$ iff $\frac{\beta_{u}}{\beta_{s}} \geq \frac{t_{u}^{*}(\alpha) w_{u}}{t_{s}^{*}(\alpha) w_{s}}$.

Proof. Since $I_{E E}(Y, E)>0$ we have that $E_{u}^{*}(\alpha) \geq E_{s}^{*}(\alpha)$ iff $I_{E}\left(Y, E_{u}^{*}(\alpha)\right) \geq$ $I_{E}\left(Y, E_{s}^{*}(\alpha)\right)$ which is equivalent to: 


$$
\begin{aligned}
\frac{-\alpha w_{u}}{\beta_{u}\left(\alpha U w_{u}+S w_{s}\right)} & \geq \frac{-w_{s}}{\beta_{s}\left(\alpha U w_{u}+S w_{s}\right)} \\
\frac{\beta_{u}}{\beta_{s}} & \geq \frac{w_{u}}{w_{s}} \alpha \\
\frac{\beta_{u}}{\beta_{s}} & \geq \frac{t_{s}^{*}(\alpha) \alpha w_{u}}{t_{s}^{*}(\alpha) w_{s}} \\
\frac{\beta_{u}}{\beta_{s}} & \geq \frac{t_{u}^{*}(\alpha) w_{u}}{t_{s}^{*}(\alpha) w_{s}}
\end{aligned}
$$

where $t_{s}^{*}(\alpha)=\frac{E_{s}^{*}(\alpha)}{\alpha U w_{u}+S w_{s}}$ and $t_{u}^{*}(\alpha)=\frac{\alpha E_{u}^{*}(\alpha)}{\alpha U w_{u}+S w_{s}}$

That is, given a level of progressivity of the tax scheme $(\alpha)$, unskilled workers prefer a higher $E$ than skilled workers if and only if the marginal effect of illegal immigration on a worker' s utility relative to what she pay to deter such illegal immigration is higher for an unskilled worker than for a skilled worker, i.e. $\frac{\beta_{u}}{t_{u}^{*} w_{u}} \geq \frac{\beta_{s}}{t_{s}^{*} w_{s}}$.

Notice that if under a less progressive government (larger $\alpha$ ) the optimal border enforcement for unskilled workers is larger than for skilled workers it is also true under a more progressive government (smaller $\alpha$ ). This result can be summarize in the following Corollary:

Corollary 1 If $\alpha_{2}>\alpha_{1}, E_{u}^{*}\left(\alpha_{2}\right) \geq E_{s}^{*}\left(\alpha_{2}\right) \Longrightarrow E_{u}^{*}\left(\alpha_{1}\right) \geq E_{s}^{*}\left(\alpha_{1}\right)$.

Given a fixed value of $\alpha$, substituting the optimal level of border enforcement in the utility function of each type of worker we obtain the workers' maximal utility for each value of $\alpha$.

$$
\begin{gathered}
U_{s}(\alpha)=\left(1-t_{s}^{*}\left(E_{s}^{*}(\alpha), \alpha\right)\right) w_{s}-\beta_{s} I\left(Y, E_{s}^{*}(\alpha)\right) \\
U_{u}(\alpha)=\left(1-t_{u}^{*}\left(E_{u}^{*}(\alpha), \alpha\right)\right) w_{u}-\beta_{u} I\left(Y, E_{u}^{*}(\alpha)\right)
\end{gathered}
$$

What is worker $i$ 's welfare effect due to a change in the progressivity of the tax scheme assuming that the government is implementing her optimal level of border enforcement? A change in $\alpha$ has two effects on worker $i^{\prime}$ s utility: 
1. A tax effect. A change in $\alpha$ implies a change in the ad valorem income tax that the worker has to pay, and therefore in her consumption. Hence, the tax effect of worker $i$ is given by:

$$
\frac{\partial c_{i}}{\partial \alpha}=-w_{i} \frac{\partial t_{i}^{*}\left(E_{i}^{*}(\alpha), \alpha\right)}{\partial \alpha}
$$

Notice that the change of the ad valorem income tax produced by a change in $\alpha$ is given by:

$$
\begin{aligned}
\frac{d t_{s}^{*}\left(E_{s}^{*}(\alpha), \alpha\right)}{d \alpha} & =\frac{\frac{d E_{s}^{*}(\alpha)}{d \alpha}\left(\alpha U w_{u}+S w_{s}\right)-U w_{u} E_{s}^{*}(\alpha)}{\left(\alpha U w_{u}+S w_{s}\right)^{2}} \\
\frac{d t_{u}^{*}\left(E_{u}^{*}(\alpha), \alpha\right)}{d \alpha} & =\frac{\frac{d E_{u}^{*}(\alpha)}{d \alpha} \alpha\left(\alpha U w_{u}+S w_{s}\right)+S w_{s} E_{u}^{*}(\alpha)}{\left(\alpha U w_{u}+S w_{s}\right)^{2}}
\end{aligned}
$$

Since from Proposition 1 we know that:

$$
\frac{d E_{s}^{*}(\alpha)}{d \alpha}>0 \quad \text { and } \quad \frac{d E_{u}^{*}(\alpha)}{d \alpha}<0
$$

we do not obtain specific signs for $\frac{d t_{s}^{*}\left(E_{s}^{*}(\alpha), \alpha\right)}{d \alpha}$ and $\frac{d t_{u}^{*}\left(E_{u}^{*}(\alpha), \alpha\right)}{d \alpha}$. Therefore, we can only conclude that the tax effect will be positive or negative, depending on the value of $\alpha$. That is, assuming that the government will implement the optimal level of border enforcement of skilled workers, a decrease of the level of progressivity of the tax scheme leads them to choose a higher optimal level of border enforcement. Depending on how intense will be such increase in border enforcement with respect to $\alpha$ their personal income tax $\left(t_{s}^{*}\right)$ will increase or decrease with $\alpha$. Similarly, if we assume that the government will implement the unskilled workers' optimal level of border enforcement, their personal income tax will increase or decrease with the level of progressivity of the tax scheme. It will also depend on the intensity of such progressivity change over the optimal level of border enforcement of unskilled workers.

2. An immigration effect. A change in $\alpha$ implies a change in the optimal level of border enforcement, and therefore, a change in the amount of illegal immigrants that will enter the country.

Thus, the immigration effect on worker $i$ is given by:

$$
-\beta_{i} \frac{d I\left(Y, E_{i}^{*}(\alpha)\right)}{d \alpha}
$$


Since from Proposition 1 we know that:

$$
\frac{d E_{s}^{*}(\alpha)}{d \alpha}>0 \quad \text { and } \quad \frac{d E_{u}^{*}(\alpha)}{d \alpha}<0
$$

we have that a decrease in the progressivity of the taxes (increase of $\alpha$ ) implies a larger optimal level of border enforcement for skilled workers and a smaller one for unskilled workers. Since $I_{E}(Y, E)<0$ we obtain:

$$
\begin{aligned}
& \frac{d I\left(Y, E_{s}^{*}(\alpha)\right)}{d \alpha}=I_{E}\left(Y, E_{s}^{*}(\alpha)\right) \frac{d E_{s}^{*}(\alpha)}{d \alpha}<0 \\
& \frac{d I\left(Y, E_{u}^{*}(\alpha)\right)}{d \alpha}=I_{E}\left(Y, E_{u}^{*}(\alpha)\right) \frac{d E_{u}^{*}(\alpha)}{d \alpha}>0
\end{aligned}
$$

Hence, an increase of $\alpha$ will reduce the number of illegal immigrants that enter the country if the optimal level of border enforcement for skilled workers is implemented. However it will increase the number of illegal immigrants if the optimal level of border enforcement for unskilled workers is implemented.

Notice also that an increase on $\alpha$ will be positive for all workers (skilled and unskilled) if the optimal level of border enforcement for skilled workers is implemented. However it will be negative for all workers if the optimal level of border enforcement for unskilled workers is implemented.

When we sum up both effects we obtain that an increase of $\alpha$ has an unambiguous total effect on worker $i$ 's welfare assuming that the government is implementing her optimal level of border enforcement. More precisely, if the government implements the optimal level of border enforcement for skilled workers an increase of $\alpha$ will make skilled workers better off. However, if the government implements the optimal level of border enforcement for unskilled workers an increase of $\alpha$ will reduce skilled workers welfare. This result is captured in the following proposition.

Proposition $3 \frac{d U_{s}\left(E_{s}^{*}(\alpha), \alpha\right)}{d \alpha}>0$ and $\frac{d U_{u}\left(E_{u}^{*}(\alpha), \alpha\right)}{d \alpha}<0$.

Proof. Let $T=\alpha U w_{u}+S w_{s}$. If the government implements the optimal level of border enforcement for skilled workers we have that: 


$$
\begin{aligned}
\frac{d U_{s}\left(E_{s}^{*}(\alpha), \alpha\right)}{d \alpha} & =-w_{s} \frac{d t_{s}\left(E_{s}^{*}(\alpha), \alpha\right)}{d \alpha}-\beta_{s} \frac{d I\left(Y, E_{s}^{*}(\alpha)\right)}{d \alpha} \\
& =-w_{s} \frac{1}{T} \frac{d E_{s}^{*}(\alpha)}{d \alpha}+w_{s} \frac{U w_{u} E_{s}^{*}(\alpha)}{T^{2}}-\beta_{s} I_{E}\left(Y, E_{s}^{*}(\alpha)\right) \frac{d E_{s}^{*}(\alpha)}{d \alpha} \\
& =w_{s} \frac{U w_{u} E_{s}^{*}(\alpha)}{T^{2}}-\left(\frac{w_{s}}{T}+\beta_{s} I_{E}\left(Y, E_{s}^{*}(\alpha)\right)\right) \frac{d E_{s}^{*}(\alpha)}{d \alpha}
\end{aligned}
$$

From the first order condition of the skilled workers' maximization problem we know that:

$$
I_{E}\left(Y, E_{s}^{*}(\alpha)\right)=\frac{-w_{s}}{\beta_{s} T}
$$

Substituting in the previous expression we have:

$$
\frac{d U_{s}\left(E_{s}^{*}(\alpha), \alpha\right)}{d \alpha}=w_{s} \frac{U w_{u} E_{s}^{*}(\alpha)}{T^{2}}>0
$$

Similarly, if the government implements the optimal level of border enforcement for unskilled workers we have that:

$$
\begin{aligned}
\frac{d U_{u}\left(E_{u}^{*}(\alpha), \alpha\right)}{d \alpha}= & -w_{u} \frac{d t_{u}\left(E_{u}^{*}(\alpha), \alpha\right)}{d \alpha}-\beta_{u} \frac{d I\left(Y, E_{u}^{*}(\alpha)\right)}{d \alpha} \\
= & -w_{u} \frac{\left(E_{u}^{*}(\alpha)+\alpha \frac{d E_{u}^{*}(\alpha)}{d \alpha}\right) T-U w_{u} \alpha E_{u}^{*}(\alpha)}{T^{2}}- \\
& \beta_{u} I_{E}\left(Y, E_{u}^{*}(\alpha)\right) \frac{d E_{u}^{*}(\alpha)}{d \alpha} \\
= & \frac{-w_{u} E_{u}^{*}(\alpha) T}{T^{2}}-\frac{w_{u} \alpha}{T} \frac{d E_{u}^{*}(\alpha)}{d \alpha}+\frac{\alpha U w_{u}^{2} E_{u}^{*}(\alpha)}{T^{2}}+ \\
& \beta_{u} \frac{\alpha w_{u}}{\beta_{u} T} \frac{d E_{u}^{*}(\alpha)}{d \alpha} \\
= & \frac{E_{u}^{*}(\alpha)}{T^{2}}\left(-w_{u} T+\alpha U w_{u}^{2}\right) \\
= & \frac{E_{u}^{*}(\alpha)}{T^{2}}\left(-w_{u}\left(\alpha U w_{u}+S w_{s}\right)+\alpha U w_{u}^{2}\right)
\end{aligned}
$$

Then we conclude that:

$$
\frac{d U_{u}\left(E_{u}^{*}(\alpha), \alpha\right)}{d \alpha}=-\frac{E_{u}^{*}(\alpha)}{T^{2}} w_{u} S w_{s}<0
$$




\subsection{Optimal $\alpha$ for a fixed $E$}

We now compute the level of $\alpha$ that maximizes the utility of each type of voters for a given value of $E$.

We have that for a given value of $E$, the optimal level of $\alpha$ for skilled workers is the solution to the following problem.

$$
\left\{\begin{array}{c}
\max _{\alpha} c_{s}-\beta_{s} I(Y, E) \\
\text { subject to }(2) \text { and }(5) .
\end{array}\right.
$$

Substituting both restrictions in the objective function the optimization problem can be written as:

$$
\max _{\alpha} w_{s}\left(1-\frac{E}{\alpha U w_{u}+S w_{s}}\right)-\beta_{s} I(E, Y)
$$

Notice that the FOC of this maximization problem is:

$$
\frac{w_{s} E U w_{u}}{\left(\alpha U w_{u}+S w_{s}\right)^{2}} \geq 0
$$

Thus, the optimal $\alpha$ for skilled workers is $\alpha_{s}^{*}(E)=1$ for all $E>0$ and any $\alpha_{s}^{*}(E) \in[0,1]$ for $E=0$. This means that for all $E>0$ skilled workers prefer a pure proportional tax scheme.

Similarly, for a given value of $E$, the optimal level of $\alpha$ for unskilled workers is the solution to the following maximization problem:

$$
\left\{\begin{array}{c}
\max _{\alpha} \quad c_{u}-\beta_{u} I(Y, E) \\
\text { subject to }(2),(4) \text { and }(5)
\end{array}\right.
$$

Notice that substituting (5) in (4) we obtain:

$$
t_{u}=\frac{\alpha E}{\alpha U w_{u}+S w_{s}}
$$

Substituting the restrictions in the objective function the optimization problem can be written as:

$$
\max _{\alpha} w_{u}\left(1-\frac{\alpha E}{\alpha U w_{u}+S w_{s}}\right)-\beta_{u} I(E, Y)
$$

Notice that the FOC of this maximization problem is: 


$$
\frac{-w_{u} E S w_{s}}{\left(\alpha U w_{u}+S w_{s}\right)^{2}} \leq 0
$$

Thus, the optimal $\alpha$ for unskilled workers is $\alpha_{u}^{*}(E)=0$ for all $E>0$ and any $\alpha_{u}^{*}(E) \in[0,1]$ for $E=0$. This means that for all $E>0$ unskilled workers prefer do not pay taxes at all.

Given a fixed value of $E$, substituting the optimal level of progressivity of the tax scheme in the utility function of each type of worker we obtain the workers' maximal utility for each value of $E$.

$$
\begin{aligned}
& U_{s}(E)=\left(1-t_{s}^{*}(E, 1)\right) w_{s}-\beta_{s} I(Y, E) \\
& U_{u}(\alpha)=\left(1-t_{u}^{*}(E, 0)\right) w_{u}-\beta_{u} I(Y, E)
\end{aligned}
$$

What is worker $i$ 's welfare effect due to a change in the border enforcement assuming that the government is implementing her optimal level of progressivity of the tax scheme? A change in $E$ has two effects on worker $i^{\prime}$ s utility:

1. A tax effect. A change in $E$ implies a change in the ad valorem income tax that the worker has to pay, and therefore in her consumption. Hence, the tax effect of worker $i$ is given by:

$$
\frac{\partial c_{i}}{\partial \alpha}=-w_{i} \frac{\partial t_{i}^{*}\left(E, \alpha_{i}^{*}\right)}{\partial E}
$$

Notice that the change of the ad valorem income tax produced by a change in $E$ is given by:

$$
\begin{aligned}
\frac{d t_{s}^{*}(E, 1)}{d E} & =\frac{1}{U w_{u}+S w_{s}}>0 \\
\frac{d t_{u}^{*}(E, 0)}{d E} & =0
\end{aligned}
$$

In this case, if the optimal level of progressivity for skilled workers is implemented, $(\alpha=1)$ an increase in $E$ will increase taxes and therefore lower skilled workers' consumption. However, if the optimal level of progressivity for unskilled workers is implemented, $(\alpha=0)$ it means that they do not pay taxes and therefore a change in $E$ won't have any effect in unskilled workers' consumption. 
2. An immigration effect. A change in $E$ implies a change in the optimal level of border enforcement, and therefore, a change in the amount of illegal immigrants that will enter the country.

Thus, the immigration effect on worker $i$ is given by:

$$
-\beta_{i} \frac{d I(Y, E)}{d E}<0
$$

When we sum up both effects we obtain that an increase of $E$ has an unambiguous total effect on unskilled workers's welfare assuming that the government is implementing her optimal level of progressivity of the tax scheme. More precisely, if the government implements the optimal level of progressivity of the tax scheme for unskilled workers an increase of $E$ will make unskilled workers better off. In this case, unskilled workers will maximizes their utility with the maximum level of $E$, i.e $E_{\max }=S w_{s}$. However, if the government implements the optimal level of progressivity of the tax scheme for skilled workers an increase of $E$ has an ambiguous effect on skilled workers welfare. Depending on how intense is the immigration effect with respect to the tax effect we have a gain or a loss in skilled workers' welfare.

\section{Political competition}

In the model described so far we have assumed that there exists a government that in order to deter illegal immigration implements a level of border enforcement $(E)$. This border enforcement policy is funded by the revenues obtained from a personal income tax over national workers $(t)$ which, by means of the level of progressivity of such tax scheme $(\alpha)$ may be different for skilled and unskilled workers. Thus, the government's choices are represented by a triplet $(E, t, \alpha)$ that satisfies the government's budget constraint. Notice that if the government's budget constraint has to be satisfied, choosing only two of these three variables determines a unique value for the third one. Without loss of generality we assume that the level of border enforcement and the level of progressivity of the tax scheme $(E, \alpha)$ are the choices of the government. Then, the ad valorem tax will be given by the government's budget constraint for each pair of values for $E$ and $\alpha$. 
In this section we analyze the political competition before the government is elected. We consider a model of two party competition. As we explained above, parties' choices are represented by the level of border enforcement and the level of progressivity of the tax scheme $\left(E_{j}, \alpha_{j}\right)$. Thus, the policy space is $X=R_{+} \times[0,1]$.

We assume that every national worker votes for a party (there is no abstention). Illegal immigrants have no right to vote ${ }^{9}$. A national worker will vote for the party whose proposal gives her a higher level of utility. That is, worker $i$ will vote for a party 1 if $U_{i}\left(E_{1}, \alpha_{1}\right)>U_{i}\left(E_{2}, \alpha_{2}\right)$ and she will vote for party 2 if $U_{i}\left(E_{2}, \alpha_{2}\right)>U_{i}\left(E_{1}, \alpha_{1}\right)$. In case of indifference, a voter is assumed to vote for each party with equal probability.

The game takes place in two stages. In the first stage, parties propose a certain policy in $X$. In the second stage each voter votes for the party whose proposal would give him a higher utility. We assume that parties are fully committed to their policy proposals. This means that the party that wins the election has to implement the policy chosen in the first stage.

The winner of the election is decided according to majority rule. In case of a tie, both parties win with the same probability (equal to $\frac{1}{2}$ ). We assume that parties maximize the probability of winning. Thus, the payoff function of a party can be defined as:

$$
V_{j}\left(E_{j}, \alpha_{j}\right)=\left\{\begin{array}{ccc}
1 & \text { if } & \#\left\{v: U_{v}\left(E_{j}, \alpha_{j}\right)>U_{v}\left(E_{k}, \alpha_{k}\right)\right\}+\frac{B}{2}>\frac{S+U}{2} \\
\frac{1}{2} & \text { if } & \#\left\{v: U_{v}\left(E_{j}, \alpha_{j}\right)>U_{v}\left(E_{k}, \alpha_{k}\right)\right\}+\frac{B}{2}=\frac{S+U}{2} \\
0 & \text { if } & \#\left\{v: U_{v}\left(E_{j}, \alpha_{j}\right)>U_{v}\left(E_{k}, \alpha_{k}\right)\right\}+\frac{B}{2}<\frac{S+U}{2}
\end{array}\right.
$$

where \# $\left\{v: U_{v}\left(E_{j}, \alpha_{j}\right)>U_{v}\left(E_{k}, \alpha_{k}\right)\right\}$ is the number of voters who prefer to vote for party $j(j \neq k)$ and $B=\#\left\{v: U_{v}\left(E_{j}, \alpha_{j}\right)=U_{v}\left(E_{k}, \alpha_{k}\right)\right\}$ is the number of voters that are indifferent between the two parties. So, if the number of voters that prefer to vote for party $j$ plus half of voters which are indifferent between the two parties is larger than the half of total voters, party $j$ will win the election.

We consider three different scenarios depending on the composition of the parties' strategy set. In the first scenario, we assume that a party has to de-

\footnotetext{
${ }^{9} \mathrm{We}$ also assume that legal immigrations have no right to vote. Thus only native workers can vote.
} 
cide about both variables simultaneously. In this case a strategy is defined as $\left(E_{j}, \alpha_{j}\right) \in X$. Thus, in this scenario parties are purely opportunistic. In the second scenario, we assume that the level of progressivity for each party is fixed and they cannot decide about it. Parties can decide only the level of border enforcement. Thus, a strategy for a party $j$ is $E_{j} \in R_{+}$. In this case, parties are ideological with respect to the progressivity of the taxes. That is, parties want to win the election in order to implement their favorite level of progressivity of the tax scheme. Finally, in the third scenario, we assume that the level of border enforcement for each party is fixed and they can decide only the level of progressivity of the tax scheme. Hence, a strategy for a party is $\alpha_{j} \in[0,1]$. In this case, parties are ideological with respect to the border enforcement policy. That is, parties want to win the election in order to implement their favorite border enforcement policy.

Since the behavior of the voters is unambiguous in this model, we define an equilibrium of the game only in terms of the strategies of the two parties at the first stage. Thus, in the first game a pure strategy equilibrium is a pair of values for the level of progressivity of the tax scheme and the level of border enforcement for each party $\left[\left(E_{1}^{e}, \alpha_{1}^{e}\right),\left(E_{2}^{e}, \alpha_{2}^{e}\right)\right]$ such that both parties are maximizing the probability of winning given the choices of the opponent. In the second game, given $\alpha_{1}$ and $\alpha_{2}$ a pure strategy equilibrium is a pair of values for the level of border enforcement $\left[\left(E_{1}^{e}\left(\alpha_{1}, \alpha_{2}\right), E_{2}^{e}\left(\alpha_{1}, \alpha_{2}\right)\right]\right.$ such that both parties are maximizing the probability of winning given the choice of the opponent. Finally, in the third game, given $E_{1}$ and $E_{2}$ fixed a pure strategy equilibrium is a pair of values for the level of progressivity of the tax scheme $\left[\alpha_{1}^{e}\left(E_{1}, E_{2}\right), \alpha_{2}^{e}\left(E_{1}, E_{2}\right)\right]$ such that both parties are maximizing the probability of winning given the choice of the opponent.

\subsection{Opportunistic parties}

Suppose that parties are purely opportunistic, i.e., they choose both the level of border enforcement and the progressivity of the tax scheme in order to win the elections.

An important variable for political parties will be the number of skilled an unskilled workers because the preferences of the median voter coincide with the 
preferences of the majority of the society.

If $S>U$ the median voter will be skilled and, in order to maximize the probability of winning, parties will try to obtain the vote of skilled workers. Given a level of progressivity of the tax scheme $\alpha$, the largest utility that a party can offer to a skilled worker is $U_{s}\left(E_{s}^{*}(\alpha), \alpha\right)$, that is, the skilled workers' utility when the government implements the optimal level of border enforcement for skilled workers. Additionally, given a positive level of border enforcement $E$, the maximum utility that a party can offer to a skilled worker is $U_{s}(E, 1)$, that is, the skilled workers' utility when the government implements the optimal level of progressivity of the tax scheme for skilled workers $\left(\alpha_{s}^{*}(E)=1\right)$.

Similarly, if $U>S$ the median voter will be unskilled and, in order to maximize the probability of winning, parties will try to obtain the vote of the unskilled workers. Given a level of progressivity of the tax scheme $\alpha$, the highest utility that a party can offer to unskilled worker is $U_{u}\left(E_{u}^{*}(\alpha), \alpha\right)$, that is, the unskilled workers' utility when the government implements the optimal level of border enforcement for unskilled workers. Additionally, given a positive level of border enforcement $E$, the highest utility that a party can offer to an unskilled worker is $U_{u}(E, 0)$, that is, the unskilled workers' utility when the government implements the optimal level of progressivity of the tax scheme for unskilled workers $\left(\alpha_{u}^{*}(E)=0\right)$

Proposition 4 When parties choose both $\alpha$ and $E$ simultaneously the unique equilibrium outcome will be a tie: both parties win the election with probability equal to $\frac{1}{2}$. Moreover, a pure strategy equilibrium will be $\left[\left(E_{s}^{*}(1), 1\right),\left(E_{s}^{*}(1), 1\right)\right]$ iff $S>U$ and $\left[\left(E_{u}^{*}(0), 0\right),\left(E_{u}^{*}(0), 0\right)\right]^{10}$ iff $U>S$.

Proof. Since both parties are a priori identical if one of them chooses $(E, \alpha)$ such that it wins the election with probability 1 it could not be an equilibrium because her opponent may choose the same $(E, \alpha)$ and win the election with probability $\frac{1}{2}$. Thus, if the outcome of the game is not a tie, matching the opponent's strategy is always a profitable deviation for one of the parties. Hence, the unique equilibrium outcome will be that both parties win the election with probability equal to $\frac{1}{2}$.

\footnotetext{
${ }^{10}$ Notice that $E_{u}^{*}(0)=E_{\max }=S w_{s}$
} 
If $S>U$ the party that offers a pair $(E, \alpha)$ such that the utility of skilled workers is higher will win the election. Given a pair of values $\left(E_{1}, \alpha_{1}\right)$ with $\alpha_{1}<1$, party 2 can win the election with probability equal to 1 choosing $E_{2}=E_{1}$ and $\alpha_{2}>\alpha_{1}$. Thus in equilibrium we must have both parties choosing $\alpha_{2}=\alpha_{1}=1$

Suppose that $\alpha_{2}=\alpha_{1}=1$ and party 1 chooses $E_{1} \neq E_{s}^{*}(1)$, then party 2 can win the election choosing $E_{2}=E_{s}^{*}(1)$. Thus, in equilibrium we must have both parties choosing $E_{1}=E_{2}=E_{s}^{*}(1)$. Hence, $\left[E_{s}^{*}(1), 1\right]$ has to be chosen by both parties at equilibrium.

Similarly, we can prove that if $U>S$, then $\left[\left(E_{u}^{*}(0), 0\right),\left(E_{u}^{*}(0), 0\right)\right]$ can be sustained as an equilibrium.

\subsection{Ideological Parties}

We present now two scenarios in which parties are ideological. We consider ideology as an strong preference on one of the policy instruments. First, we suppose that parties' ideology is determined by the progressivity of the tax scheme and finally that it is determined by the intensity of protection against illegal immigration.

\subsubsection{Parties' Ideology determined by $\alpha$}

Suppose that the level of progressivity of the tax scheme is fixed for both parties (and different for different parties). We will denote by leftist party the party which is committed to a higher level of progressivity of the tax scheme $\left(\alpha_{l}\right)$ and rightist party the one committed to a lower level of progressivity $\left(\alpha_{r}>\alpha_{l}\right)$. Ideology can be interpreted in this game as the progressivity of tax schemes offered by parties. In this case parties only have to propose the level of border enforcement. We can interpret this scenario to countries in which the immigration become an important issue recently and parties do not have an ideological position yet on it.

If $S>U$, the median voter will be skilled and political parties will center their proposals on skilled workers. Notice that the best that a party can do in this case is to chose the optimal level of border enforcement for skilled workers, given its own value of $\alpha$. That is $E_{s}^{*}\left(\alpha_{l}\right)$ for the leftist party and $E_{s}^{*}\left(\alpha_{r}\right)$ for 
the rightist party. From Proposition 3 we know that $\frac{d U_{s}\left(E_{s}^{*}(\alpha), \alpha\right)}{d \alpha}>0$. Since $\alpha_{r}>\alpha_{l}$, it implies that $U_{s}\left(E_{s}^{*}\left(\alpha_{r}\right), \alpha_{r}\right)>U\left(E_{s}^{*}\left(\alpha_{l}\right), \alpha_{l}\right)$. Therefore, the rightist party has a strategy that guarantees him a sure win.

Similarly if $U>S$, since $\frac{d U_{u}\left(E_{u}^{*}(\alpha), \alpha\right)}{d \alpha}<0$ and $\alpha_{r}>\alpha_{l}$, we have that $U_{u}\left(E_{u}^{*}\left(\alpha_{l}\right), \alpha_{l}\right)>U\left(E_{u}^{*}\left(\alpha_{r}\right), \alpha_{r}\right)$. Therefore the leftist party can win the election supporting $E_{u}^{*}\left(\alpha_{l}\right)$.

Those levels of border enforcement may constitute a particular pure strategy equilibrium for each case. We calculate all the possible pure strategy Nash equilibria of the game and we state them in the following Proposition:

Proposition 5 Suppose $\alpha_{l}<\alpha_{r}$ are fixed and parties choose E:

(i) if $S>U$ the rightist party has a nonempty set of strictly dominant strategies $E_{r} \in R_{+}$s.t. $U_{s}\left(E_{r}, \alpha_{r}\right)>U_{s}\left(E_{s}^{*}\left(\alpha_{l}\right), \alpha_{l}\right)$ and the equilibrium outcome of the election is rightist party wins the election with probability 1.

(ii) if $U>S$ the leftist party has a nonempty set of strictly dominant strategies $E_{l} \in R_{+}$s.t. $U_{u}\left(E_{l}, \alpha_{l}\right)>U_{u}\left(E_{u}^{*}\left(\alpha_{r}\right), \alpha_{r}\right)$ and the equilibrium outcome of the election is leftist party wins the election with probability 1.

Proof. If $S>U$ the winner of the election is the party that offers the level of border enforcement that makes skilled workers better off. Then given a level of progressivity of the tax scheme such that $\alpha_{l}<\alpha_{r}$, the best replies for each party can be written as:

$$
\begin{aligned}
B R_{l} & =\left\{\begin{array}{l}
E_{l} \in R_{+} \text {s.t. } U_{s}\left(E_{l}, \alpha_{l}\right)>U_{s}\left(E_{r}, \alpha_{r}\right) \text { if } E_{r} \in R_{+} \backslash K \\
E_{l} \in R_{+} \text {if } E_{r} \in K
\end{array}\right. \\
B R_{r} & =\left\{E_{r} \in R_{+} \text {s.t. } U_{s}\left(E_{r}, \alpha_{r}\right)>U_{s}\left(E_{l}, \alpha_{l}\right) \text { for all } E_{l} \in R_{+}\right\},
\end{aligned}
$$

where $K \equiv\left\{E \in R_{+}\right.$s.t. $\left.U_{s}\left(E, \alpha_{r}\right)>U_{s}\left(E_{s}^{*}\left(\alpha_{l}\right), \alpha_{l}\right)\right\}$ represents the set of dominant strategies for the rightist party. It is no empty since $E_{s}^{*}\left(\alpha_{r}\right) \in K$.

Then since, $U_{s}\left(E, \alpha_{r}\right)>U_{s}\left(E, \alpha_{l}\right)$ for all $E \in R_{+}$we have that if the rightist party chooses a level of border enforcement $E_{r} \in K$ then this party will win the election with probability 1 . Hence, $\left[\left(E_{l} \in R_{+}\right) ;\left(E^{r} \in R_{+}\right.\right.$s.t. $\left.\left.U_{s}\left(E_{r}, \alpha_{r}\right)>U_{s}\left(E_{s}^{*}\left(\alpha_{l}\right), \alpha_{l}\right)\right)\right]$ are the pure strategy equilibria of the game and the outcome of the election will be that the rightist party wins with probability 1. 
When $U>S$ the proof is similar to the one written above.

Figure 1 represents the range of equilibrium values for the level of border enforcement chosen by the rightist party when $S>U$.

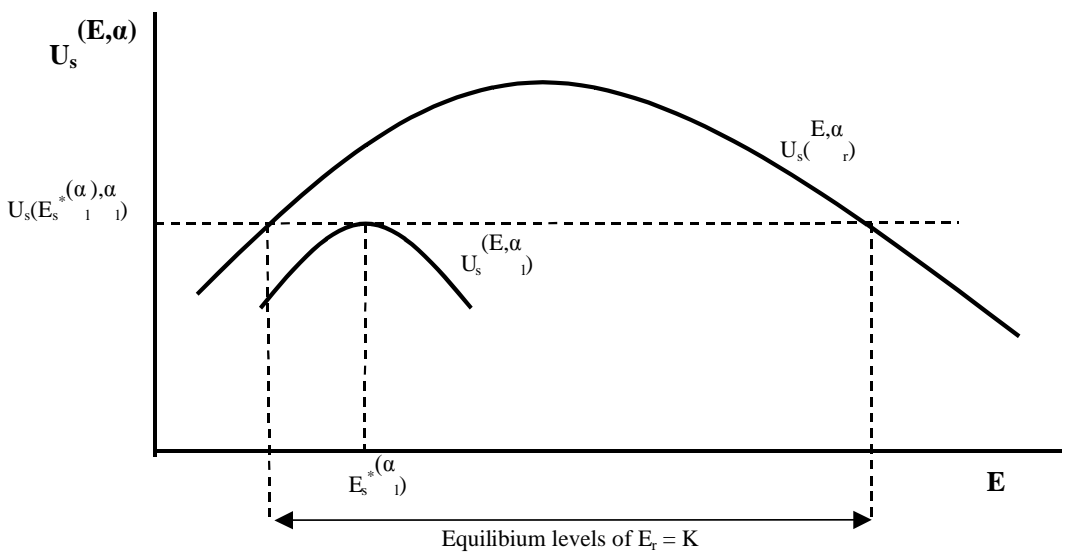

Range of Equilibrium Levels of $E_{r}$

To summarize, whenever Parties' ideology is determined by $\alpha$, rightist party has an advantage to capture skilled workers' vote, and leftist party has an advantage to capture unskilled workers' vote. Thus, the outcome of the election is totally determined by the composition of the population.

\subsubsection{Parties' Ideology determined by $E$}

We will assume now that parties are committed to implement a specific border enforcement policy. We denote by leftist party the party which is committed to a lower level of border enforcement and rightist party the one committed to a higher level of border enforcement (i.e. $E_{r}>E_{l}$ ). Thus, ideology can be interpreted in this game as the intensity of protection against immigration. Assuming that the level of border enforcement is fixed for parties they only have to propose a level of progressivity of their tax schemes. We can interpret this 
scenario to countries in which the immigration become for some time an issue and parties have already an ideological position on it.

If $S>U$ the median voter will be a skilled worker and given a certain level of border enforcement $E$, any political party will try to propose a value for $\alpha$ in order to give skilled workers a level of utility higher than the one offered by her opponent. Since the level of border enforcement is given, the number of illegal immigrants entering the country is also given. Thus, parties will want to offer a value for $\alpha$ that minimizes the tax imposed to skilled workers.

Given a fixed value of $E$, the optimal value of $\alpha$ for skilled workers is $\alpha=1$. Thus, the maximal utility that party $j$ can offer to skilled workers given a fixed value of $E_{j}$ is $U_{s}\left(E_{j}, 1\right)$. Then, if $U_{s}\left(E_{l}, 1\right)>U_{s}\left(E_{r}, 1\right)$ the leftist party has a nonempty set of dominant strategies that guarantees her a sure victory (this set will include $\left.\alpha_{l}=1\right)$. Otherwise if $U_{s}\left(E_{r}, 1\right)>U_{s}\left(E_{l}, 1\right)$ the rightist party has a nonempty set of dominant strategies that guarantees her a sure victory (this set will include $\left.\alpha_{r}=1\right)$. Finally, if $U_{s}\left(E_{r}, 1\right)=U_{s}\left(E_{l}, 1\right)$ then both parties can assure a tie by choosing $\alpha_{j}=1$.

Notice that if both parties choose the value for $\alpha$ that minimizes the tax imposed to skilled workers (i.e. $\alpha_{j}=1$ ) the rightist party will win the election iff $U_{s}\left(E_{r}, 1\right)>U_{s}\left(E_{l}, 1\right)$. That is:

$$
\frac{-\left(I\left(Y, E_{r}\right)-I\left(Y, E_{l}\right)\right)}{E_{r}-E_{l}}>\frac{\frac{w_{s}}{U w_{u}+S w_{s}}}{\beta_{s}}
$$

We state the previous result in the following Proposition.

Proposition 6 Suppose $E_{r}>E_{l}$ are fixed and parties choose $\alpha$ then if $S>U$ we have that the rightist party has a nonempty set of strictly dominant strategies and the equilibrium outcome of the election is rightist party wins the election with probability 1 iff:

$$
\frac{-\left(I\left(Y, E_{r}\right)-I\left(Y, E_{l}\right)\right)}{E_{r}-E_{l}}>\frac{\frac{w_{s}}{U w_{u}+S w_{s}}}{\beta_{s}}
$$

The inequality written in the proposition is composed by two positive terms since $E_{r}>E_{l}$ and $I_{E}(Y, E)<0$. The one in the left hand side represents the impact of a change in border enforcement policy on the number of illegal immigrants entering the country. That is the efficacy of the border enforcement. 
The one in the right hand side represents the participation on the financing of the border enforcement policy for an skilled worker relative to her illegal immigration marginal effect when both parties propose the minimum level of progressivity $\alpha_{j}=1$.

This Proposition shows that the efficacy of border enforcement policy $\left(\frac{-\Delta I(Y, E)}{\Delta E}\right)$ matters. In particular, if efficacy is higher enough rightist party surely wins the election. However, since $I_{E E}(Y, E)>0$, efficacy is decreasing on $E$ which means that the lower level of border enforcement committed to by both parties the higher the probability of winning for the rightist party.

More comparative statics can be done. For instance, as skilled workers' negative concern about illegal immigration increases (higher values of $\beta_{s}$ ) skilled workers will tend to vote for the rightist party and she will be more likely to win the election. In this context, one can think that rightist parties might have an interest to rise skilled workers' negative perception about illegal immigration.

Also, since $I_{E Y}(Y, E)<0$, i.e. efficacy of border enforcement is increasing on the potential illegal immigration, a higher potential illegal immigration will help rightist parties to win the election. Hence, rightist party is more likely to win as the external threat is higher.

Similarly, if $U>S$, the median voter will be unskilled and given a certain level of border enforcement $E_{j}$ any party would choose a value of $\alpha_{j}$ in order to give to unskilled workers a higher utility level than her opponent. As we have seen above, since the level of illegal immigration is given parties will offer a value of $\alpha_{j}$ in order to minimize the tax imposed to unskilled workers to fund the given level of border enforcement.

In this case, given a fixed value of $E$, the optimal value for the unskilled workers is $\alpha=0$. Thus the maximal utility that party $j$ can offer to unskilled workers given a fixed value of $E_{j}$ is $U_{u}\left(E_{j}, 0\right)$. Then, if $U_{u}\left(E_{r}, 0\right)>U_{u}\left(E_{l}, 0\right)$ the rightist party has a nonempty set of dominant strategies that guarantees her a sure victory (this set will include $\alpha_{l}=0$ ). Otherwise if $U_{u}\left(E_{l}, 0\right)>U_{u}\left(E_{r}, 0\right)$ the leftist party has a nonempty set of dominant strategies that guarantees her a sure victory. Finally, if $U_{u}\left(E_{r}, 0\right)=U_{u}\left(E_{l}, 0\right)$ then both parties can assure a tie by choosing $\alpha_{j}=0$.

We know that $U_{u}\left(E_{r}, 0\right)>U_{u}\left(E_{l}, 0\right)$ iff: 


$$
0>\beta_{u}\left(I\left(Y, E_{r}\right)-I\left(Y, E_{l}\right)\right)
$$

But this condition is always satisfied since $E_{r}>E_{l}$ and $I_{E}(Y, E)<0$. So, we can conclude that the rightist party always wins the election choosing the maximum level of progressivity of the tax scheme $\alpha_{r}=0$. We set this result on the following proposition.

Proposition 7 Suppose $E_{r}>E_{l}$ are fixed and parties choose $\alpha$ then if $U>S$ the rightist party has a nonempty set of strictly dominant strategies and the equilibrium outcome of the election is rightist party wins the election with probability 1.

Proof. Since $E_{j}$ is given we have that $U_{u}\left(E_{j}, \alpha_{j}\right)$ is a decreasing function of $\alpha_{j}$. Thus, the maximal utility that party $j$ can offer to unskilled workers given a fixed value of $E_{j}$ is $U_{u}\left(E_{j}, 0\right)$. Given $E_{r}>E_{l}$ if both parties choose $\alpha_{j}=0$ we have that:

$$
U_{u}\left(E_{r}, 0\right)-U_{u}\left(E_{l}, 0\right)=\beta_{u}\left(I\left(Y, E_{l}\right)-I\left(Y, E_{r}\right)\right)>0
$$

Therefore, the rightist party has a nonempty set of strictly dominant strategies (which include $\alpha_{r}=0$ ) and the equilibrium outcome of the election is rightist party wins the election with probability 1.

So, whenever parties' ideology is determined by border protection, composition of the population does not entirely determine the outcome of the election. More precisely, in countries in which there are more unskilled than skilled workers rightist party has an advantage to capture the unskilled workers' vote. So, in this case, composition of the population determines the political outcome. However, in countries where there are more skilled than unskilled workers, skilled workers will vote for the rightist party if their optimal level of border enforcement is high enough. Thus, in this case, the outcome of the election does not only depend on the composition of the population but also in some parameters such as $\beta_{s}$ or $Y$. So that, for values of $\beta_{s}$ or $Y$ large enough, rightist parties have an advantage to win independently on the population structure of the country. 


\section{Concluding Remarks}

In this paper we ask ourselves whether ideology can be useful for parties to win elections when the relevant issue is the control of immigration. In order to answer this question we analyze different scenarios depending on whether parties are either opportunistic or ideological. In addition, assuming ideological parties, we consider different cases depending on whether ideology is either determined by the level of border enforcement or by level of progressivity on the tax scheme. Using a very simple two party competition model we find the following conclusions:

1. When parties are purely opportunistic, i.e. they can choose both $E$ and $\alpha$, in equilibrium, they always tie and choose the same pair of policies. This equilibrium policies coincide with the optimal ones for the median voter. However, when parties are ideological in equilibrium there is a unique winner and the policies implemented may not be the optimal ones for the median voter. Therefore, in general ideology gives a party an advantage to win the election.

2. If illegal immigration is a new phenomenon in the host country, i.e. parties' ideology is determined by $\alpha$, in equilibrium, the rightist party always wins the election in developed countries (where the majority of population is skilled) while the leftist party always wins in developing countries (where the majority of population is unskilled). The intuition behind this result is that voters will vote for the party who gives them a cheaper border enforcement. Obviously, the rightist party (less progressive party) may offer a cheaper border enforcement to skilled workers while leftist party (more progressive party) may offer a cheaper border enforcement to unskilled workers. Thus if the median voter is skilled the rightist party wins otherwise if the median voter is unskilled the leftist party wins.

3. If illegal immigration has been an issue for some time in the host country, i.e. parties' ideology is determined by $E$, in equilibrium, the rightist party always wins the election in developing countries (where the majority of the population is unskilled). That is because political competition make parties choose high levels of progressivity which implies that the optimal level of border enforcement for the median voter (unskilled) will be also high. Therefore, the most anti-immigrant party has an advantage to win the election. 
However, in developed countries (where the majority of the population is skilled) the political outcome depends on other variables such as the skilled workers' perception about the relationship between illegal immigration and insecurity, and the efficacy of the border enforcement policy. In this context, we find that if skilled workers believe more intensively that illegal immigration is linked to delinquency and to insecurity, in equilibrium, the rightist party (the most anti-immigrant party) wins more likely. In addition, we find that as the border enforcement policy is more efficacious, in equilibrium, the rightist party wins more likely. Both results seem to be quite intuitive since either a higher effect of illegal immigration on skilled workers' utility or a high efficacy of the border enforcement make skilled workers (the majority of the population) prefer a higher level of border enforcement.

4. In this context, with respect to the efficacy of the border enforcement we assume that it is increasing in the number of potential illegal immigrants. Then, the higher the number of potential illegal immigrants the more likely the rightist party wins the election in equilibrium.

5. Regarding the policy implications, in countries where illegal immigration is a new phenomenon there is no policy implication because the composition of population determines the political outcome. However, in countries where illegal immigration is an old phenomenon we find some policy implications. In this type of countries we want to emphasize the conflict of interests between the rightist and leftist party about some aspects such as the concern that skilled workers have about illegal immigration and the efficacy of the border enforcement policy. As far as our results are concerned a natural implication is that the rightist party would have interests in rise the concern about illegal immigration among skilled workers and improve the efficacy of the border enforcement policy. Nevertheless, the leftist party would have interests in reduce the concern about illegal immigration among skilled workers and lower the efficacy of the border enforcement policy. 


\section{References}

[1] Borjas, G. J. "The economics of immigration", Journal of Economic Literature, 1994, pp. 1667-1717.

[2] Borjas, G. J; Freeman, R; Katz, L. F. "Searching for the Effects of Immigration on the Labor Market", American Economic Review, 1996, v. 86, iss. 2, pp. $247-251$

[3] Chritopher J. Ulrich. "Alien-Smuggling Uncontrolled Migration in Northern Europe and the Baltic Region", The European Institute for Crime Prevention and Control, af filiated with the United Nations. HEUNI paper $N^{o}$ 7. May 1995.

[4] Cooper, R. N. "Immigration to the United States", The Trilateral Comission (Europe). $27^{\text {th }}$ European Meeting In Porto. Session on the Euro-Mediterranean Partnership: The U.S. case Study. October 2003.

[5] Coronado, R; Orrenius P. M. "The Impact of Illegal Immigration and Enforcement on Border Crime Rates", Research Department Working Paper. Federal Reserve Bank of Dallas. March 2003.

[6] Ethier, Wilfred J. "Illegal Immigration: The Host Country Problem", American Economic Review, March 1986, v. 76, iss. 1, pp. 56-71.

[7] European Commision. Justice and Home affairs, "European Citizens and Freedom, Security and Justice. Qualitative Survey of Citizens of the 15 Member States and the 13 Applicant Countries". March 2003. URL: http://europa.eu.int/comm/justice_home/doc_centre/intro/docs/eurobaro _qualitatif_en.pdf

[8] Fairchild Henry P. "The Restriction of Immigration", American Economic Re view, March 1912, v 2, iss. 1, pp. 53-62.

[9] Garfinkel Michelle R. "Domestic Politics and International Conflict", American Economic Review, December 1994, v 84, iss 5, pp. 1294-1309.

[10] Goud, Eric D; Mustard, David; Weinberg, Bruce A. "Crime rates and Local Labor Market Opportunities in the United States: 1979-1997", Re view of Economics and Statistics, February 2002, v. 84, iss. 1, pp. 45-61 
[11] Grogger, Jeff. "Market Wages and Youth Crime", Journal of labor Economics, October 1998, v.16, No. 4, pp. 756-791.

[12] Hanson, Gordon H; Robertson, Raymond; Spilimbergo, Antonio. "Does Border Enforcement Protect U.S. Workers from illegal immigration?", Review of Economics and Statistics, February 2002, v. 84, iss. 1, pp. 73-92.

[13] Hanson, Gordon H; Spilimbergo, Antonio. "Political Economy, Sectoral Shocks, and Border Enforcement", Canadian Journal of Economics, August 2001, v. 34, iss. 3, pp. 612-638.

[14] Karidis, V. "Criminality or Criminalization of Migrants in Greece?", in V. Ruggiero et al. (eds): The New European Criminology, London and New York: Routledge, 1998.

[15] Machin, Stephen; Meghir, Costas. "Crime and Economic incentives", Working papers W00/17 Institute for Fiscal Studies, 2000.

[16] Mayda, A. M. "Who is Against Immigration? A Cross-Country Investigation of Individual Attitudes toward Immigrants", Working Paper, January 2003.

[17] Orrenius, Pia M. "Illegal Immigration and Enforcement along the U.S.Mexico Border: An Overview", Federal Reserve Bank of Dallas Economic and Financial Review, 1st Quarter 2001, v. 0, iss. 1, pp. 2 11.

[18] Razin, A; Sadka, E; Swagel, P. 2002. "Tax Burden and Migration: A Political Economy and Evidence. Journal of Public Economy. 